FORTHCOMING, CAPITAL MARKETS LAW JOURNAL (2012).

\title{
MAKing A Voluntary Greek Debt Exchange Work
}

\author{
Mitu Gulati \\ Duke University \\ Jeromin Zettelmeyer \\ European Bank for Reconstruction and Development and CEPR
}

Draft Date: January 31, 2012

\begin{abstract}
Within the next couple of months, the Greek government, is supposed to persuade private creditors holding about EUR 200bn in its bonds to voluntarily exchange their existing bonds for new bonds that pay roughly 50 percent less. This may work with large creditors whose failure to participate in a debt exchange could trigger a Greek default, but may not persuade smaller creditors, who will be told that their claims will continue to be fully serviced if they do not participate in the exchange. This paper proposes an approach to dealing with this free rider problem that exploits the fact that with some probability, the proposed exchange might be followed by an involuntary restructuring some time in the future. The idea is to design the new bonds that creditors are offered in the exchange in a way that make them much harder to restructure than the current Greek government bonds. This is easy to do because the vast majority of outstanding Greek government bonds lack standard creditor protections. Hence, creditors would be offered a bond that performs much worse than their current bond if things go according to plan, but much better if things do not. They will accept this instrument if (1) the risk of a new Greek debt restructuring in the medium term is sufficiently high; and (2) there is an expectation that the next restructuring probably will not be voluntary.
\end{abstract}




\title{
Making A Voluntary Greek Debt Exchange Work
}

\author{
Mitu Gulati \\ Duke University \\ Jeromin Zettelmeyer \\ European Bank for Reconstruction and Development and CEPR ${ }^{1}$
}

Draft Date: January 31, 2012

\section{Introduction}

According to an understanding reached at the summit of European heads of government on October 26, 2011, the Greek government, within the next few months will attempt to persuade private creditors holding about EUR 200bn in its bonds to voluntarily take a 50 percent reduction of the face value of their bonds. In a hypothetical scenario where all of the Greek bonds were held by a handful of big creditors, they could likely be persuaded to take the haircut. The argument would be that the failure to grant Greece relief would worsen its financial condition and eventually result in political chaos and default. Under those conditions, creditors would be lucky to get anything close to 50 percent. Arguments to that effect were made, often effectively, to persuade the holders of syndicated loans to Latin American sovereign debtors in the 1980 s to voluntarily take significant reductions in their holdings.

However, according to calculations by J.P. Morgan, only about EUR 120 bn of Greek government bonds are held by large institutional investors such as banks, pension funds, and insurance companies. This leaves up to EUR 80bn in the hands of asset managers, sovereign wealth funds, and some retail investors. For the most part, these holders are seeking to maximize returns and have no desire to build reputations as co-operators with the Eurozone governments. The fact that roughly EUR $120 \mathrm{bn}$ worth of bonds will be tendered by the big regulated holders means that Greece will come out of the exchange with a reduced debt load and will be better able to pay its creditors. Under those conditions, the question for the non-institutional investors is: Why tender, especially if the exchange is voluntary in the sense that Greece is expected to continue its debt service to non-tendering creditors after the exchange?

Adding to the complications is that the border between the categories of a large regulated holder and holdouts is porous. The large holders, once it becomes clear that the primary pressures to take the 50 percent cut are going to be their size and identities, will have an incentive to engage in arbitrage. The result will be that

\footnotetext{
${ }^{1}$ The views expressed in this paper are those of the authors and should not be taken to represent the views of EBRD or any other institutions that the authors are affiliated with. Without implication, conversations and comments by Erik Berglof, Charles Blitzer, Patrick Bolton, Lee Buchheit, Ross Buckley, Marcos Chamon, Andres De La Cruz, Anna Gelpern, Olivier Jeanne, Thomas Laryea and Shahin Vallee as well as seminar participants at the ECB and EBRD are gratefully acknowledged.
} 
more and more bonds will end up in the hands of those who can extract the highest value from engaging in a holdout strategy. This is particularly true since the regulators in question (the ones who are supposed to apply the pressure on these institutions to take the 50 percent haircut) have conflicting incentives. While they want these institutions to tender in the exchange, they also have an interest in the institutions being as financially strong as possible. If selling on the open market to a hedge fund will yield a higher value, then there will be a temptation to allow at least the weakest of these institutions to sell.

On the face of it, the proposal to do the Greek exchange on a voluntary basis seems to run into a devastating free rider problem. Free rider problems are not new in the context of debt exchanges - all bond exchanges since the Brady deals have had to deal with this problem in some form. ${ }^{2}$ However, the great majority of these exchanges addressed the problem by maintaining some ambiguity as to whether nonparticipating creditors would in fact be repaid - that is, the exchanges were conducted under the threat of default. ${ }^{3}$ This approach has so far been ruled out for Greece. And, as of this writing, policy makers also appear reluctant to utilize any legal approach that involves a change in the payment terms of the bonds against the will of dissenting bondholders. In particular, this reduces the possibility of dealing with the free rider problem by "retrofitting" a collective action clause on the Greek bonds, which could be achieved through domestic Greek law. ${ }^{4}$

This paper addresses the question of whether it is conceptually and legally possible to design the Greek debt exchange in a way that (i) is voluntary in the sense that the government promises to continue servicing its debt to creditors regardless of whether they accept the debt exchange offer or not; (ii) achieves a 50 percent "haircut" of the Greek debt and (iii) eliminates the free rider problem. The answer, after a lot of brain-racking, is a qualified Yes. We proceed in two stages.

- We begin by asking what incentives a potential holdout might possibly have to accept a 50 percent haircut from a government that is at the same time reassuring him or her that it will continue honoring its debts in full even if the

\footnotetext{
${ }^{2}$ See,Federico Sturzenegger \& Jeromin Zettelmeyer, Creditors' Losses versus Debt Relief: Results from a Decade of Sovereign Debt Crisis, 5 J. EuR. ECoN. Assoc. 343-51 (2007), for a detailed account and Ran Bi, Marcos Chamon, \& Jeromin Zettelmeyer, The Problem That Wasn't: Coordination Failures in Sovereign Debt Restructurings, IMF Working Paper WP/11/265 (2011).for an analysis of how the free rider problem was overcome in these exchanges.

${ }^{3}$ There were three notable exceptions, i.e. cases of purely voluntary debt exchanges in the context of debt crises: Russia's July 1998 GKO-to-Eurobond exchange, in which US\$ 4.4bn worth of short term local currency bills were swapped into 7 and 20 year Eurobonds; Argentina's June 2001 "Mega Swap", a maturity lengthening operation comprising about US $\$ 29$ bn of mostly US\$ denominated debt; and Turkey's June 2001 debt exchange, which swapped about US\$7.7bn of short term local currency debt into US $\$ 8.5$ bn of medium term, mostly dollar-linked new debt. However, these cannot serve as models for Greece because none involved a "haircut", which is a requirement of the October $26^{\text {th }}$ EU-IMF plan. Furthermore, the July 1998 Russian and June 2001 Argentine exchanges were soon followed by devastating defaults. See FEDERICO STURZENEGGER \& JeROMIN ZeTTELMEYER DEBT DEFAULTS AND LESSONS FROM A DECADE OF CRISES (2007) for details and Joshua Aizenman, Kenneth M. Kletzer \& Brian Pinto, Sargent-Wallace Meets Krugman-Flood-Garber, or: Why Sovereign Debt Swaps Do Not Avert Macroeconomic Crises, 115 ECON J. 343 (2005).for an interpretation of why these exchanges failed to solve the crises.

${ }^{4}$ See Lee C. Buchheit \& Mitu Gulati, How to Restructure Greek Debt. Duke Law Working Paper 47. (2010) (available at http://papers.ssrn.com/sol3/papers.cfm?abstract_id=1603304).
} 
creditor prefers to hold on to its old bonds. Indeed, a holder of Greek debt that matures soon is unlikely to have any such incentive. But a bondholder whose amortisation is still several years off might well have. The reason, ironically, is the possibility that even a 50 percent haircut of Greece's privately held debt might not be enough to restore Greece to solvency. That is, with some probability, even a successful Greek debt exchange may be followed by an additional debt restructuring operation after a few years. If this probability is viewed as sufficiently high, and holders of the new Greek government debt offered in the exchange can expect to survive that second restructuring in much better shape than the holders of the old debt, this would remove the incentive to free ride.

- Next, we ask whether there are ways in which the Greek government can design the new debt instruments to make them much more "restructuring proof" than the existing debt instruments. The answer turns out to be Yes, in part because the existing instruments offer virtually no creditor protection. We explore two approaches. The first is to legally subordinate the old instruments to the new ones - meaning that in the event of a new debt restructuring, the old instruments would be repaid only after the new instruments have been repaid in full. The problem with this approach is that it will constitute a default event under the terms of a standard sovereign Credit Default Swap (CDS) contract, which European policy makers have so far tried to avoid. The second approach is to subordinate the old instruments de facto but not de jure, by making the new instruments more difficult to restructure. This latter option would probably not trigger CDS contracts.

In the section that follows, we first present a characterisation of the standard free rider problem in debt exchanges. We describe the way in which this is typically solved, the complications added by the requirement of voluntary participation, and whether and how these complications can be addressed in principle. We then go on to describe two legal strategies through which this solution could be implemented. Finally, we present some back-of-the-envelope calculations to establish whether the approach discussed might in fact be sufficient to dissuade free riders. The conditions under which this would be the case turn out to be stringent, but could be met, provided that investors expect any additional restructuring to be involuntary. The latter is plausible, if the current strategy to restore Greece to solvency falters in the near term. Without new Greek borrowing from the private markets, the fraction of official sector debt in the Greek debt stock will likely continue to increase in the near term. Assuming that the official creditors remain unwilling to take a haircut, the private sector haircut required to restore solvency the next time around will be that much higher.

\section{A Framework for Thinking About Incentives to Free Ride}

A typical debt pre-default exchange offer - that is, one which does not necessarily insist on "voluntariness" in the sense defined in the introduction - tries to persuade creditors to tender using a version of the argument that a bird in hand is preferable to two in the bush. That is, the offer is designed to create a risk-return tradeoff. The new bond offered will typically be lower in net present value than the old bond if both are discounted at the same rate. However, accepting the new bond is 
safer than holding on to the old bond, because there is ambiguity about whether the old bond will in fact be honored. As a result, the creditor that is trying to decide whether to accept the offer may find that the value of the new bond exceeds the expected value of the old bond.

Figure 1 illustrates this simple decision problem from the perspective of a creditor who is small enough to free ride. If the creditor accepts the exchange offer, she receives a payoff $1-h$ per unit of the old bond tendered with probability 1 , where $h$ denotes the haircut suffered by tendering investors. If she rejects the offer, she will be repaid in full with some probability, denoted $p .{ }^{5}$ With probability $1-p$, the debtor defaults, in which case the creditor receives some (low) recovery value $v_{O}<1-h$. The creditor accepts if $1-h \geq p+(1-p) v_{O}$. That is, for a given haircut, the creditor accepts the offer if the probability of receiving full repayment on the old bonds is sufficiently low.

Figure 1.

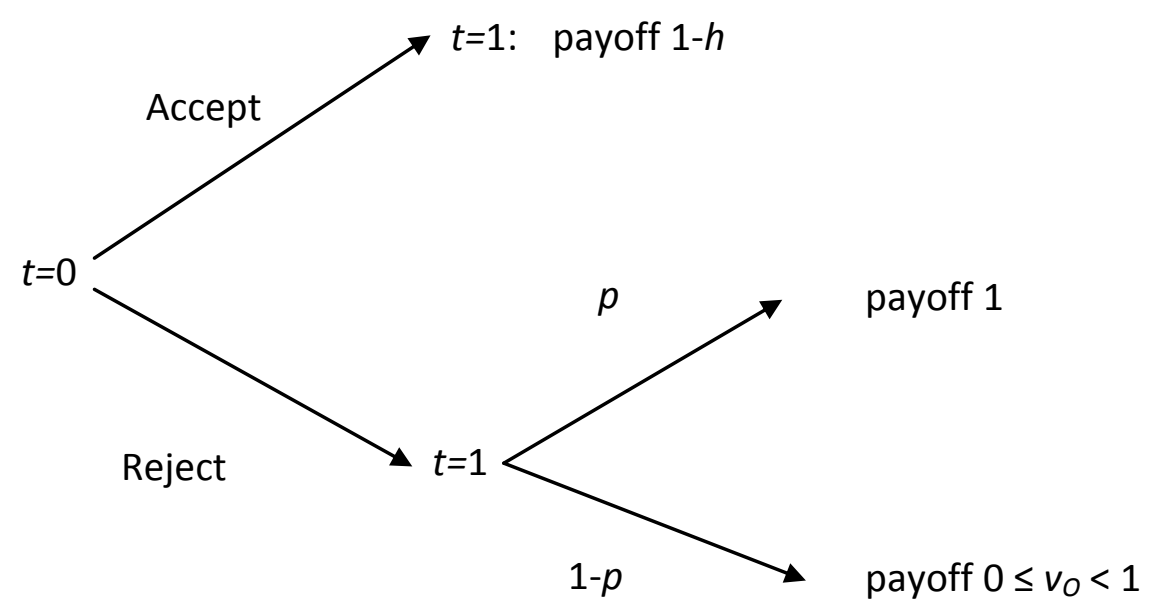

Now, suppose that the debtor insists that the exchange is "voluntary" in the sense defined in the introduction, that is, it promises to service the debt of any holdout in full. Assume that this removes any ambiguity about whether the old debt will be repaid. In Figure 1, this would mean that $p=1$. The implication is that for any $h>0$, the exchange offer would always be rejected: clearly, a safe payment of 1 is preferable to a safe payment of $1-h$. Hence, if this is the right characterisation of the decision problem, then a "voluntary" haircut is inconsistent with a positive haircut. Making the offer "voluntary" removes any risk-return trade off. Rather than comparing a bird in hand with two in the bush, the creditor is faced with the choice of one bird in hand versus two birds in hand, and will always opt for the latter.

However, Figure 1 embodies an assumption that makes it potentially misleading. The assumption is that participating creditors face no sovereign risk after having accepted the haircut $h$. In a case like Greece, which is unlikely to go back to its pre-crisis credit rating immediately even after a successful debt exchange involving a large haircut, this is surely too strong. Figure 2 describes the creditor decision

\footnotetext{
${ }^{5}$ This is where we have used the assumption that the creditor is small enough to free ride. If the creditor were large, non-participation would always trigger default, i.e. $p=0$.
} 
problem after this assumption is dropped, where 1- $\pi$ denotes the sovereign risk associated with the new bonds, and $v_{N}$ the recovery value of the new bonds in the event of default. The decision rule for accepting the offer becomes:

$$
\pi(1-h)+(1-\pi) v_{N} \geq p+(1-p) v_{O}
$$

Hence, the creditor's decision will be influenced by the default risk and the recovery value of the new bonds as well as by the default risk and recovery value associated with the old bonds.

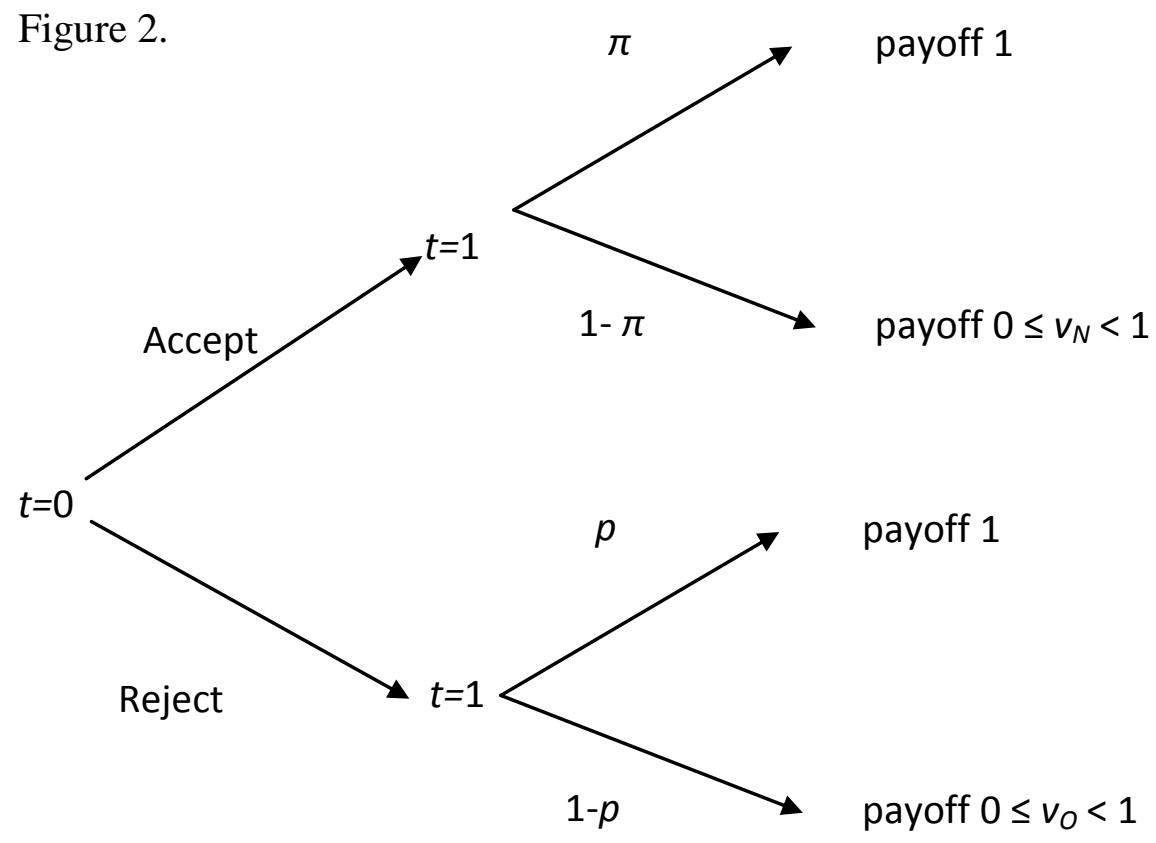

The question is now what "voluntariness" of an exchange offer means in the framework described by Figure 2. The answer to this turns out to hinge on the maturity the old debt held by the prospective holdout creditor.

- if the old debt is short term, in the sense that it comes due immediately or very soon after the debt exchange, then $p=1$ arguably remains the right characterization of "voluntariness" from the perspective of a small creditor. That is, the sovereign promises to repay holdouts and does so, because the debt is in fact due more or less at the time of the promise.

- if, however, the old debt is medium or long term, then it is subject to some default risk - just like the new debt. At most, the debtor can promise that the default risk faced by the hold out will be as low as the default risk faced by the creditor that accepts the offer: $p=\pi$. 
In the case of Greece, just over EUR 34 bn of bond amortizations fall due in 2012, out of the approximately EUR 257 bn due from end-2011 onward. This implies that most debtors are in the second camp. ${ }^{6}$

We now return to the title question of the paper: can a debt exchange offer be both voluntary and involve a haircut? The answer is No if the old debt is short term, but Yes in principle if it is not. Using $p=\pi$, the decision rule for accepting the debt exchange offer becomes:

$$
\pi \leq\left(v_{N}-v_{O}\right) /\left(v_{N}-v_{O}+h\right)
$$

That is, for a given $h>0$, a holder of medium or long term sovereign bonds might accept a debt exchange offer if:

- the probability of full repayment $\pi$ is sufficiently low, and

- the recovery value associated with the new bonds, $v_{N}$, is sufficiently high relative to the recovery value associated with the old bonds.

To summarize: except for holders of very short term debt, the promise to continue servicing the old debts along with new bonds with lower debt service does not necessarily make holding out a dominant strategy, because there may be a state of the world where the new bonds perform better than the old bonds. As long as there is no default, the creditor is obviously better off by holding on to the old bonds. But if the new bonds have higher value in the event of a default or involuntary restructuring, and if the probability of such a restructuring is sufficiently likely, this will make the new bonds the "safer" option, and possibly more attractive than the old debt.

The question, discussed in the next section, is what the debtor can do to ensure that the new bonds are, in fact, "safer" in this sense.

\section{Legal Techniques to Maximise Participation in a Voluntary Debt Exchange}

The techniques discussed in this section exploit the fact that the vast majority of outstanding Greek bonds are domestically issued instruments that do not contain standard creditor protection clauses such as a "pari passu" clause prohibiting legal subordination, a "negative pledge clause" prohibiting the issuance of new collateralised debt unless existing debt is enhanced in the same way, and a crossdefault clause that defines a default on another government bond as a default event. ${ }^{7}$ This is typical for the majority of the debt Eurozone countries issued after the adoption of the common currency, albeit with some variations across countries (Table 1). As a result, it is relatively straightforward for the Greek sovereign to adopt measures that would put creditors in a better position to recover value in a future default if they choose to part with their existing instruments.

\footnotetext{
${ }^{6}$ Source: Greek Ministry of Finance information (Public Debt Bulletin, September 2011), and calculations based on Boomberg data.

${ }^{7}$ Of the EUR 260bn of Greek government bonds outstanding as of end-September 2011, 242bn were issued domestically (see Hellenic Republic Public Debt Bulletin No. 63, September 2011).
} 
Table 1. Characteristics of Local-Law Government Bonds of Selected Eurozone Countries

\begin{tabular}{|l|l|l|l|l|l|l|}
\hline Country & $\begin{array}{l}\text { Local } \\
\text { Law }\end{array}$ & Acceleration & Modification & $\begin{array}{l}\text { Cross } \\
\text { Default }\end{array}$ & $\begin{array}{l}\text { Negative } \\
\text { Pledge }\end{array}$ & $\begin{array}{l}\text { Pari } \\
\text { Passu }\end{array}$ \\
\hline Ireland & Yes & No & No & No & No & No \\
\hline Belgium & Yes & Yes & No & No & No & Yes \\
\hline Greece & Yes & Yes & No & No & No & No \\
\hline Spain & Yes & No & No & No & No & Yes \\
\hline Portugal & Yes & No & No & No & No & Yes \\
\hline Italy & Yes & Yes & No & Yes & Yes & Yes \\
\hline
\end{tabular}

Source: The essential terms of the contracts were obtained from offering documents available on Thomson One Banker and Dealogic.

\section{$\underline{\text { Technique One: Legal Subordination }}$}

Pari passu clauses assure lenders that they will rank equally with the holders of all other unsubordinated debt. This means that the sovereign debtor cannot take actions that have the effect of legally subordinating the holder of the bond that has a pari passu clause. An example of such a subordination would be the sovereign passing a law saying that it will pay one set of creditors ahead of another set. In order to incentivize creditors to enter into its exchange offer in 2005, Argentina attempted to do something along these lines. First, it announced in its exchange offer that it planned to service only the new bonds tendered in the exchange i.e. that it had no plans to resume debt service on any of the old bonds (which had been in default since the end of 2001). Second, it passed a law (the "Padlock law") that constrained it from negotiating a new deal with the bondholders who had not entered into the exchange. Arguably, the holdouts had been legally subordinated. ${ }^{8}$

Ordinarily, sovereigns cannot take such actions because they have agreed to pari passu clauses in all of their bonds. Since the vast majority of Greek bonds, however, lack pari passu clauses, Greece can pass a law saying that the bondholders who exchange their bonds for the 50 percent haircut will have priority, in terms of getting paid first out of tax revenues, over the holders of Greek government bonds without pari passu clauses who do not tender. Such a law would be consistent with the contractual terms of Greek government bonds.

Furthermore, legal subordination of this type may be consistent even with the spirit of a voluntary debt exchange. This is because (unlike the case of Argentina) the old bonds would continue be serviced as long as all goes according to plan - that is, holdouts would continue to get paid following the debt exchange. Indeed, if the combination of a debt exchange, fiscal adjustment and growth restore the sustainability of Greek debt, the old bondholders would get repaid in full. But the law could specify that in the event of a new debt restructuring, this would first affect the

\footnotetext{
${ }^{8}$ For more on the Padlock law, see Rodrigo Olivares-Caminal, To Rank Pari Passu or Not to Rank Pari Passu: That is the Question in Sovereign Bonds after the Latest Episode of the Argentine Saga. 75 L. \& BUS. REV. OF THE AMERICAS 745 (2009). A New York court, in late 2011, bought the argument that the Argentine Padlock law had indeed violated the pari passu clause.
} 
holders of the old bonds, and could only begin to affect the holders of the new debt if the old debt is written down to zero.

\section{Complications}

There is a question of whether subordination stipulated by domestic law, along the lines described above, would be credible. From the perspective of committing a sovereign, domestic law is not a strong device. It could simply be changed in the future, lifting the requirement of legal subordination (although it is not clear why the government would want to do that). Hence, subordination is ultimately based on a government promise. The question is whether creditors would find this promise from the Greek government to be sufficiently credible such that few or no holders will be tempted to hold out. One argument might be that domestic political economy may generally work in favour of keeping such promises -- why treat a particular class of creditors better ex post if you have already told them and your voters that they will be subordinated?

Second, legal subordination would trigger CDS contracts. One of the triggers in the standard sovereign CDS is an act of subordination (which we take to mean legal subordination). We do not take a position in this paper as to whether avoiding triggering CDS payouts is a good public policy objective or not - arguments can be made both ways. ${ }^{9}$ However, it seems clear that the desire to avoid triggering of CDS contracts is one of the main motivations what European policy have been insisting on "voluntary" exchanges. Hence, an attempt by Greece to formally subordinate its old bonds to new bonds would most likely run into resistance from the European Union partners backing its rescue package.

\section{Technique Two: Relative Difficulties of Restructuring}

This technique - which as best as we can tell, would not trigger CDS contracts - is effectively a reverse engineered Exit Exchange offer. It will help, therefore, to first describe the Exit Exchange technique, which was originally devised as a means of deterring holdout creditors. ${ }^{10}$ (see Buchheit and Gulati, 2000).

\footnotetext{
${ }^{9}$ The main argument against triggering CDS contracts is to avoid contagion, since CDS protections may have been written by systemic financial players. Against this, it can been argued both that the outstanding net CDS exposures related to Greece appear to be small (about EUR 4bn) and that the failure to trigger CDS contracts in a debt restructuring involving a large haircut would result in even more contagion, as investors owning such protection with respect to other Eurozone countries realise that it is not effective, and seek to reduce their exposures directly. In the same vein, it has been argued that that avoiding CDS protection in the case of Greece would do long-term damage to the CDS market, as it is demonstrated the CDS contract can be circumvented. However, the possibility of circumventing CDS contracts in the case of Greece may be an artefact of the divergence between default events as defined in the CDS contracts and creditor losses that can be imposed without a default event when government bonds lack proper creditor protections. Hence, it is well possible that newly issued CDS contracts will simply adapt to this fact, which may benefit the CDS market in the long run. ${ }^{10}$ See Lee C. Buchheit, Lee \& Mitu Gulati, Exit Consents in Sovereign Bond Exchanges, 48 UCLA L. REV. 59-84 (2000).
} 
The Exit Exchange technique was devised to tackle the difficulty created by the fact that sovereign bonds governed by New York law, prior to 2003, typically required unanimous approval from the bondholders before any reduction in payment terms on the bonds as a whole could occur. Alterations of non-payment terms, however, could occur with something between a 50 percent and 66.67 percent vote typically. The Exit Exchange technique took advantage of this latter characteristic of the bonds. Once the approval of a large enough fraction of the bondholders to the proposed exchange was achieved, these holders would be given new bonds (with the agreed upon haircut) and in exchange, while handing in their old bonds, the old holder would agree to eliminate key contractual protections from the bonds that remained untendered (that is, the holdouts). So, the holdouts could find themselves holding bonds with no negative pledge, pari passu, cross default, and acceleration provisions. They could also find their bonds delisted and governed by the law of some jurisdiction that would be unsympathetic to holdouts (e.g., the sovereign's own courts). The unattractiveness of being left holding the bag, so to speak, was enough to induce dramatically high participation rates in at least three exchanges that were done using this technique in Ecuador (2000), Uruguay (2003) and the Dominican Republic (2005).

At bottom, the key to the success of the Exit Exchange technique is that no bondholder wants to be left holding a contract that has significantly worse contract rights than the others. This is because, in the event of another financial crisis, it is the bonds with the weaker contract provisions that will both suffer first and the most.

If the Exit Exchange technique were used with Greek government bonds (for example, with its small subset of English and Swiss law bonds), it would likely trigger the CDS contracts because the use of the Exit Consent technique would be viewed as inducing an involuntary exchange. However, the large majority of Greece's current bonds already have extremely weak contract provisions (no cross default, negative pledge, or pari passu) and are governed by the law of a jurisdiction likely to be sympathetic to the debtor and unsympathetic to holdouts. In other words, there is no need to conduct exchange offer with the exchanging bondholders vote to worsen the contract protections of their brethren (and that is the arguably coercive and ugly part of an Exit Exchange offer). In the Greek case, all that needs to be done is for the bondholders in the exchange to be given better terms. If the exchanging bondholders are given new contracts that provide the comforting warmth of strong contract protections - modification terms with high vote thresholds (maybe an 85 percent requirement to alter payment terms in the future ${ }^{11}$ ), cross defaults, negative pledge clauses, pari passu provisions, foreign law, etc. - then that will make it perilous to remain out in the cold with a contract that provides no protection. And the larger the number of bonds that move into the world of hard-to-restructure contracts, the greater the peril the holders of easy-to-restructure bonds will be in when and if Greece returns to financial distress. Any bondholder doubting this reality has only to look back at the Brady restructurings of the 1980s where the sovereign bonds, especially those governed by New York law, were largely left untouched because of how difficult it

\footnotetext{
${ }^{11}$ The typical English-law or New York-law governed sovereign bond requires a 75 percent vote of the bonds (in principal amount) before payment terms can be altered. Offering the existing Greek bondholders a vote threshold higher than 75 percent, under English-law or New York-law, has the potential of not only attracting the holders of Greek-law governed bonds, but also the holders of English-law Greek bonds.
} 
would have been to restructure them relative to the syndicated loans that constituted the majority of the sovereign debt then. In other words, while bonds were not legally senior, they were treated as de facto senior. ${ }^{12}$

\section{Complications:}

For the foregoing to work, the holders of the current contract-lite Greek bonds have to fear that that there is a real likelihood that Greece might return to financial distress in the near future. As things stand, this scenario has some plausibility. The current deal gets Greece to only a debt to GDP ratio of 120 percent, excluding the impact of collateral enhancements that might be given to these creditors or additions to the debt stock triggered by the need to recapitalise local banks.

Further, holders of the current bonds have to believe that the next time around, the debt restructurers will not be constrained by instructions such as the exchange needs to be voluntary. The pronouncements of the Eurogroup on November 28, 2010, when it was announced at all Eurozone sovereign bonds issued after June 2013 would contain CACs, arguably push in this direction. The recent EU summit on December 9, 2011 affirmed both that the Greek debt problem and the modalities to resolve it are viewed as "unique and exceptional" in Europe, and that CACs will be included in the terms and conditions of all new euro government bonds.

Finally, the technique may not be sufficient to incentivize the roughly 7 percent of Greek bondholders who already own English-law and Swiss-law bonds with all of necessary contract protections. Other than (possibly) a higher voting threshold, the exchange would give them only what they already have. The fact that these holders cannot easily be pushed into the exchange, however, should remind the holders of domestic law bonds of the value of having bonds with strong contract protections.

\section{Would it Work? A Back-of-the-Envelope Calculation}

The final question that we seek to address is whether the incentive offered by making the new debt either legally or de-facto senior would be sufficiently strong to convince creditors to accept new debt instruments along the lines described in the October $26^{\text {th }}$ Euro summit communiqué. This requires an estimate of what these instruments would be worth to investors in net present value terms compared to the old instruments that they would be tendering. Doing so is complicated by the fact that negotiations between Greece and creditor representatives have so far been inconclusive, so that no actual exchange offer has been published yet. However, we know that the Euro summit stipulated "a nominal discount of 50 percent on notional Greek debt held by private investors" and also set aside an official Eurozone contribution of EUR 30 bn, presumably to finance either a cash "sweetener" or the collateralisation of principal. Since the total volume of privately held Greek bonds is

\footnotetext{
${ }^{12}$ See Patrick Bolton \& Olivier Jeanne, Structuring and Restructuring Sovereign Debt: The Role of Seniority, 76 REV. ECON. STUD. 879 (2009).
} 
in the order of EUR $200 \mathrm{bn}$, this implies that the bond offer is likely to contain either 15 cents on the Euro in cash payouts, or alternatively collateralised principal worth 15 cents on the Euro in net present value terms.

For illustrative purposes, we focus on one specific proposal that was discussed between Greece and its creditors which meets these conditions, namely, a 20 year, 35 percent amortizing discount bond with 10 years grace on principal, coupon of 5.6 of new principal, and an upfront cash payment of 15 percent of old principal. The sum of the cash payment and the face value of the new bond add up to 50 percent of the face value of the old bond, as required by the Eurozone summit. The question is what this bond would be worth to bondholders, on average, in net present value terms, and what the implicit net present value "haircut" is, defined as the percentage difference between new and old bonds, evaluated at a common discount rate. ${ }^{13}$

Table 2 contains the answer for three discount rate assumptions: 5 percent, which may be thought of as close to Greece's typical medium term borrowing rate in normal times (assuming a future German Bund rate of about 3 percent, this corresponds to a spread of about 200 basis points); 9 percent (corresponding to the highest spreads suffered by Italy and Spain in the second half of 2011), and 13 percent, which can be taken as representing the yield after a debt exchange that falls short of fully restoring fiscal credibility. The first line of the table shows the present value of the assumed new bonds using these discount rates uniformly for all payments. The second shows the "haircut" in the definition typically used by market practitioners, namely, 100 (the face value of the old bond) minus the present value of the new bond. Finally, the last line shows the net present value loss that the average bondholder would suffer by accepting the debt exchange, using the same discount rate to discount the old debt as is used to discount the new debt. ${ }^{14}$

Table 2. "Haircuts" Implicit in October 26, 2011 Debt Restructuring Parameters for Greece: Illustrative Example 1/

(in percent)

\begin{tabular}{lccr}
\hline & \multicolumn{3}{c}{ Assumed discount rate } \\
\cline { 2 - 4 } & 5 & 9 & 13 \\
\hline Value of new bonds & 52.2 & 40.4 & 33.3 \\
"Market" haircut & 47.8 & 59.6 & 66.7 \\
NPV haircut & 48.0 & 52.2 & 54.6 \\
\hline 1/ Assumed terms for new bond: 20 year 35\% amortizing discount bond with 10 \\
years grace on principal, coupon of 5.6\% of new principal, and an upfront cash \\
payment of 15\% of old principal. Calculations assume that all Greek government \\
bonds coming due after January 1, 2012 are tendered. Net present values \\
computed on the basis of tendering on January 1, 2012.
\end{tabular}

\footnotetext{
${ }^{13}$ For a discussion of alternative approaches to computing "haircuts", see Sturzenegger and Zettelmeyer, supra note 2; and Jeromin Zettelmeyer How to do a Sovereign Debt Restructuring in the Eurozone: Lessons from Emerging Market Debt Crises, in Guntram Wolff \& William Cline (eds.), RESOLVING THE EUROPEAN DEBT CRISIS (2012).

${ }^{14}$ The fact that this "net present value" haircut is somewhat lower than the haircut in the definition of market practitioners is standard; this reflects the fact that the face value of the old bonds which is used in the computation of the latter is higher than their present value. See Zettelmeyer, supra note 13.
} 
The bottom line is that the 50 percent face value discount that the EU leaders committed to on the October $26^{\text {th }}$ summit is likely to translate into an average NPV haircut in about the same range, based on a plausible example of what the bond offer might look like, and a range of discount rate assumptions. Hence, for the purpose of the back-of-the-envelope calculation that follows, we treat face value and present value haircuts to be the same, i.e. we ignore any discounting for the purposes of this calculation.

In line with Figure 2, we assume that there are two relevant states: one in which following the completion of the current exchange there is no further default or restructuring, assumed to happen with probability $\pi$, and one in which there is such a restructuring. If there is a new restructuring, it is assumed to happen fairly soon after the current debt exchange, so that any coupon payments to holders of both new or old bondholders between the time of the exchange and the new restructuring can be ignored. ${ }^{15}$ In this case, bondholders face a simple trade-off:

- If they opt for the new bonds, they will receive a cash payout of 15 cents on one Euro of old principal immediately, and 35 cents later with probability $\pi$. With probability $(1-\pi)$, i.e. in the event of a new restructuring, they will receive a recovery value of $v_{N R} \leq 35$.

- If they hold on to their old bonds, they will receive full repayment of 100 cents on the Euro with probability $\pi$, and a recovery value of $v_{O} \leq 100$ if there is a new restructuring.

As discussed before, the voluntariness of the exchange is expressed in the fact that the probability of receiving something less than the contractually promised terms, $\pi$, is the same regardless of whether bondholders chose to accept the exchange offer or not. However, the recovery values of the new bonds and the old ones in the event of a future restructuring may be different.

Absent any other incentive, a risk-neutral individual bondholder should opt for participation if:

$$
15+\pi^{*} 35+(1-\pi) v_{N R} \geq \pi^{*} 100+(1-\pi) v_{O}
$$

which can be rewritten as a condition on the probability that there will be no further restructuring, $\pi$ :

$$
\pi \leq\left[15+v_{N R}-v_{O}\right] /\left[65+v_{N R}-v_{O}\right]
$$

\footnotetext{
15 If one assumes a longer intervening period, one would need to take into account that because of the principal reduction, coupon payments on the new debt are only about 40 percent (in absolute terms) of coupon payments on the old debt. An easy way of taking this into account in the back-of-the-envelope calculation is to express the cash payout received by the new bondholders net of this difference. For example, if there is one coupon payment in the intervening period, the holder of the new bond would receive $15+5.6 * 0.35$ prior to the second restructuring, while she would have receive about 4.5 (the average coupon on the old debt) if she had hold on to the old bonds. The difference is 12.4. For a twoyear intervening period, the difference would be about 9.8 , and so on.
} 
This formula states that to generate an incentive for small bondholders to accept the exchange, the probability $\pi$ that there will be no future restructuring must not be higher than a particular threshold, which depends on the difference between the expected recovery values of the new and old bonds. The larger this difference, the higher the threshold probability can be.

To obtain an intuition for what this means in practice, it is useful to consider some special cases:

First, consider the case in which the expected recovery values of the new and old bonds are the same (this could be achieved, for example, through a law that says that in the event of a new restructuring, the face value of the remaining old bonds is written down first to that of the new bonds, before being serviced equally). In that case, $\pi \leq 15$ / $65=0.23$. This is perhaps an implausibly low probability of avoiding a new restructuring. Hence, merely promising to treat the old and then new debt the same in the event of a future debt restructuring is unlikely to be enough to ensure high participation.

Second, we seek to establish the maximum value of $\pi$ that would still avoid of free riding. This is obtained by setting $v_{N R}=35$ and $v_{O}=0$. Hence, $\pi_{\max }=50 / 100=$ 0.50 . This means that by setting $v_{O}$ sufficiently low relative to $v_{N R}$, the exchange will succeed (in the sense of avoiding the free rider problem) as long as investors view the likelihood of a further restructuring to be at least 50 percent.

Finally, consider an intermediate case. Pessimistic market observers have argued that the haircut suffered by private investors would need to be far higher, in the order of 80 percent, to restore Greece to solvency. Assuming some holdouts, 80 percent is hence a plausible assumption for the maximum haircut that investors expect on the new debt in the event that a new restructuring is needed. Hence $v_{N R} \geq 20$. Suppose now that the old debt is strictly subordinated to the new debt (legally or de facto) in a new restructuring. Since the new debt would not be repaid in full in the event of a new restructuring, this means $v_{O}=0$. Using the minimum recovery value of $v_{N R}=20$ for the participating bondholders implies $p \leq 35 / 85=0.41-$ not an unreasonable level, given the political and economic uncertainty prevailing in Greece and Europe at the moment. Importantly, this level could be higher if investors are risk averse, since risk averse investors will particularly value the fact that acceptance of the exchange offer implies a "bird in hand" (15 cents on the dollar of cash right away, plus 35 if they are lucky) rather than "two birds in the bush" (100 cents on the dollar if they are lucky).

The back-of-the-envelope calculations above are for the average bondholder. Short term bondholders (on a residual maturity basis) will face higher haircuts - in the order of 67 percent - but as already argued, they will in any case have no incentive to tender if the success in the exchange rules out an involuntary restructuring for about one year. Note also that the calculations above assume that the bondholder that needs to be persuaded to join the exchange does not enjoy CDS protection. For a CDSprotected creditor, $v_{O}=100$, since the creditor will collect full repayment in the event of an involuntary restructuring. Hence, rejecting the debt exchange offer is a dominant strategy: regardless of whether or not a further restructuring materialises, the investor expects to be repaid in full. However, the volume of CDS protection written for 
Greece is limited (with reportedly about EUR 4bn of net exposure), and the horizon of some of this protection is likely to be short, as very little new protection is likely to have been written in the last two years.

Hence, under the assumptions made, perhaps up to EUR40 bn of debt would still not be tendered. Hence, "success" in this exchange means a participation rate of 80 percent (EUR 160 bn out of the targeted 200) or higher.

\section{Conclusion}

The notion of a voluntary debt exchange with a 50 percent haircut seems oxymoronic. Why would investors - or at least small investors, that individually have no impact on the success of the exchange - voluntarily accept a 50 percent writedown of their claims?

This paper has shown that in the special circumstances of Greece, there may nonetheless be a way of designing debt exchange offer that meets these seemingly contradictory objectives. This possibility arises due to three facts, which jointly make the Greek case fairly unique.

First, under the terms of the debt restructuring envisaged in the October 26, 2011 EU Summit declaration, Greek debt might become manageable, but would remain high, at 120 percent of GDP. As a result, there is a possibility that Greece may be faced with future debt distress even if it achieves a 50 percent haircut with large creditor participation. Such a situation is very likely to result in an involuntary restructuring. The reason for this is that - as private sector debt is gradually repaid and replaced with IMF-EU debt - the private sector haircut required to restore Greece to solvency would no longer be achievable using a voluntary approach.

Second, although some of the outstanding Greek debt will come due in 2012, most will not. Hence, in the event that a second restructuring is required in 2013 to restore Greece to solvency, most of the holders of current Greek debt would be "hit". The same would be true (with less force) if a new restructuring were to happen in 2014. When deciding whether or not to tender their debt in the voluntary exchange that is currently envisaged, most investors hence need to worry not just about the haircut associated with that exchange, but also about how they might fare in the event of a new restructuring.

Third, most outstanding Greek government bonds are domestic law bonds that offer minimal creditor protections: no pari passu clause, no negative pledge clause, no cross-default clause. The implication of this is that in the event of an involuntary restructuring they would offer minimal creditor protection.

The implication of these three facts is both that it is easy to design new Greek bonds that do much better in protecting the creditor in the event of a Greek default than most of the currently outstanding instruments, and that Greek bond holders should take this extra protection seriously. In the presence of bonds that are much harder to restructure - because they are issued under foreign jurisdiction and expose the sovereign to litigation in the even of an involuntary restructuring - the holders of 
current Greek government bonds may well bear the brunt of a future restructuring. Even if they are not subordinated de jure, they may find themselves subordinated de facto.

Back of the envelope calculations suggest that avoiding this risk, together with a 15 percent cash payout (or equivalently, collateralisation of principal in the same amount) offered to accepting creditors, may generate sufficiently strong incentive to make creditors accept a 50 percent debt exchange offer - provided that the risk of a new restructuring is viewed as sufficiently high, in the order of at least 50 percent.

Hence, the answer to the question of why creditors might be willing to voluntarily accept a 50 percent haircut is: "Because in a situation of high uncertainty and continued sovereign risk, switching into new bonds that give investors 15 cents on the Euro in cash and at the same time put them in a better position to recover value in a default might be more attractive than holding on to the current debt."

Ironically, it is the lack of faith of the market that a reduction of the Greek public debt ratio to 120 percent is enough to make Greece's debt sustainable that may help to make Greece's latest plan work. If offered new bonds with stronger creditor protections and a cash payout, this lack of faith may lead to high creditor participation even in a voluntary bond exchange involving a high haircut. After that exchange, Greece will still face an uphill battle if it wants to avoid a further restructuring. But contrary to a situation when creditor participation in the initial exchange is low, it is a battle that it might win. 